\title{
MANAGEMENT OF OPERATIONAL RISK COSTS: DEALING WITH CONFLICTS OF INTERESTS AND SENSITIVE CLIENT SITUATIONS IN AUDIT FIRMS
}

\author{
S. Deevski* \\ Department of Industrial Business, University of National and World Economy, Sofia, Bulgaria
}

\begin{abstract}
The purpose of this paper is to look into the challenges of management of potential operational risk costs by dealing with conflicts of interests and sensitive client situations in audit firms. Furthermore, the author's goal is to propose a framework addressing those risks proactively and thus minimizing the potential costs that might arise from such situations. The paper starts with an introduction to the importance of understanding the concepts of conflict of interest situations and sensitive client situations, and why it is often crucial for the leadership and professionals working for audit firms to address the risks arising from them. The author presents a framework, containing policies and procedures for operational risk management with respect to conflicts of interest and sensitive client situations. The proposed framework is tested via a comprehensive survey among a number of audit firms. The results of the survey show that all of the surveyed companies have implemented at least some of the proposed policies and procedures. The results also show that there is a general agreement among the leadership teams of the audit firms that adopting a comprehensive operational risk management framework would benefit the audit firms in the long term minimizing its costs.
\end{abstract}

Key words: cost management, operational risk management, audit

\section{INTRODUCTION}

The purpose of this paper is to look into the challenges of management of potential operational risk costs by dealing with conflicts of interests and sensitive client situations in audit firms. "Operational risk" for the purpose of the paper is defined as the risk of loss due to failure and deficit of internal processes, people and systems or from external events, and includes legal risk. Operational risk management is maintained mainly through the risk management instrument in support of and achievement of corporate objectives. A company's mission, vision and general strategic orientation are closely related to the company's risk behavior. The aforementioned are strongly influential to the corporate culture and thus to the opinions, attitudes and values of the employees. Organizations should be

\footnotetext{
*Correspondence to: Stoyan Deevski, Department: Industrial Business, University of National and World Economy, 1404 Sofia, 6 Kestenova gora, str., Telephone number: +359 885861 392, E-mail address: sdeevski@unwe.bg
}

focused both on the compliance with regulatory requirements and on the adoption of the operational risk management frameworks by the leadership and the employees (1). The entire work environment is important for actually implementing a risk strategy.

The analysis is based on another aspect of the risk management - risk management framework that is concerned with the ethics and code of conduct proliferation. It aims at detection and prevention of conflicts of interests and sensitive client situations in the audit firms and thus addressing the risks arising from them.

\section{DISCUSSION}

The conflicts of interest are driven by acts of employees in order to make a personal gain or to cause a damage and in most cases, subsequently this might be directed against the employer - the audit company in particular. Those conflicts of interests are present when the independence of the leadership and professionals is breached. The independence of 
the management and the staff is vital and it is in the public interest in respect of which they provide assurance opinions. Reliance of third parties on the assurance opinions is reinforced by the independence of the audit firms. Being independent defines objectivity, this is the state of mind which permits conclusions being unaffected by influences that distort professional judgement and thus allowing for integrity, professional skepticism and objectivity.

In order to stress a good sense of integrity, objectivity and professional skepticism, significant facts and circumstances should be thoroughly disclosed. Management and staff members must not undertake a professional activity if a circumstance or relationship would unduly influence the individual's professional judgement regarding that activity. A broad range of circumstances and relationships might enforce different independence risks. A certain circumstance or relationship could cause one or more of the following threats:

- Financial or other interest might inappropriately influence an individual's judgement or behavior and thus causing self interest threat.

- Threat that the current service provided may be influenced by results of previous judgement or inappropriate evaluation of a firm and its personnel could form an inadequate judgement.

- Advocacy threat is another distortion of the independence that arise from the promotion of client's position so eagerly that objectivity in this way might be lost.

- A well-known threat amongst the audit firms is probably being too familiar with a client as a result of a long and close relationship. Professionals' judgement is highly likely to be biased when a professional is being too concerned with client's interests.

- Intimidation threat, the threat that a firm or its personnel will be discouraged from acting objectively because of actual or perceived pressures, including attempts to exercise undue influence over the firm or individual.

Historically auditing is an ethically precarious profession. Auditor's primary focus is to represent the public interests instead of client interests. Controversy to that is the fact that auditors are compensated by the clients and this brings many complicated professional issues. The auditor frequently receives substantial client fees for both auditing and non-auditing services, yet, he is expected to provide an impartial endorsement of financial statements.

It is widely trusted by the public that the audit professionals perform their assignments proficiently. Subsequently, it is well accepted that the stronger the confidence of the public in certified public accountants is, the higher the duty for trustworthiness of the accountants. By certifying the public reports that collectively depict a corporation's financial status, the independent auditor assumes a public responsibility transcending any employment relationship with the client. The independent public accountant performing this special function owes ultimate allegiance to the corporation's creditors and stockholders, as well as to the investing public. This 'public watchdog' function demands that the accountant maintain total independence from the client at all times and requires complete fidelity and public trust.

Professional issues arise also from the sensibility of the information to which the auditor has access. Therefore, in case impropriety is discovered an auditor should be careful about the disclosure and publications he makes, because the situation might lead to risk of violating confidentiality. Violating confidentiality on its behalf brings the risk of facing litigation and damaging clients' trust, ending up in higher operational and legal costs. The auditor is constantly facing difficulty in making cost benefit decisions when it comes to the effort that should be put in the determination of which data should be disclosed, as the quantity and quality of the information gathered require individual discretion and judgement.

On the other side, there is a risk when withholding the release of such information of ending up being legally negligent. Such situations could lead to loss of current clients as well as loss of potential prospects and thus bearing opportunity costs. Another cost of such sensitive client situation is the loss of reputation from being overly lenient. In order to prevent such situations, the occurrence of a conflict of interest is to be avoided. The paper later stresses on the costs arising from such events and the approaches to mitigate them.

It is widely perceived that auditors usually work under stress and we should give a credit 
to structural shortcomings like time pressure as well. Audit firms operate largely though strict budgets as a technical control for the pricing of engagements, allocation of resources and expost evaluation. The amount and quality of time that an employee uses are often hardly monitored and stay unobserved and this is where the structural shortcomings arise. The opportunities for supervision of staff and management becomes scarce. Given that, this is where also the framework takes significant role. A well developed ethical framework which is widely disseminated by the tone of the top might advocate of code of conduct in which the employee recognizes himself with the company's ethics and integrity objectives. In those cases less supervision would be required and thus some payroll costs (as part of operational) could be avoided.

Auditor's legal liabilities are limited but when breaches of them arise auditors undergo heavy litigation and might incur substantial penalties. Furthermore, the role of audit reputation on the interaction between the auditor as a witness to the manager's actions are examined. This contrasts with the analyses how the firm's owner uses auditor reputation as a means of signaling to external constituencies. Subject to auditing is the production of information which facilitates the interactions between the shareholders and its executives. Management reports are inclined to be typically biased when management is acting on its own behalf and does not recognize itself with the shareholder's objectives and when it is acting in favor of personal benefits, this is also an example of conflict of interest. This is where the auditor's work becomes a necessity and a demand for confirmation of the financial statements provided by managers is created. The auditor is able to provide such confirmation in case he is induced to be truthful and fair in his judgements and conclusions. This reputation formation on its behalf have another aspect of the benefits for the costing but in this case for its clients. Auditor's work substitutes costly contracting, monitoring and litigation born by the shareholders. By deterring misreporting, reputation reduces the inherent risk of the audit, allowing the auditor to cut back on substantive testing without increasing the probability of biased reports. The presence of audit institutions that promote and facilitate the building of auditor reputations mitigate both the auditor's and the manager's moral hazard on actions and reports. This role of reputation has implications for auditor legal liability, because the auditor would aim to avoid penalties that will affect his reputation (2).

To sum up, there are several ethical problems auditors are facing. Large fees received for engagements might be factors for biased position of the auditors. This problem is often exasperated through additional fees being earned for non-auditing services. The public is placing auditors in high regard and this increases the auditor's responsibility to provide unbiased opinions. Furthermore, structural shortcomings make the aforementioned problems even more intense in the audit companies. Thus, it is imperative that the profession equips auditors with a strong ethical awareness in order to prepare them to successfully meet ethical challenges.

In general, there are costs attached to avoidance and prevention, assessment and management of such risks as well as costs that are involved in an actual harm caused by a particular conflict situation. To minimize the risk to the organization's reputation for integrity, the appearance of such conflicts of interest should be avoided and prevented in case they arise. Conflicts of interest could be as damaging to the trust in the public.

Reputation in the context of the corporate world is based on perceptions of the characteristics, performance and the behavior of a company. In other words, reputation is the reflection of how well or how adverse different groups of stakeholders think of commercial brands. Corporate reputation influences investment decisions of interested parties. There is a positive correlation between the good reputation of an auditing company confirming true and fair financial statements and good investment and business decisions (3).

An example of a big corporation acquiring a smaller one can illustrate the issue. Those deals are usually evaluated based on audited financial data. Most of the financial ratios and analysis are using financial accounting data in its calculations. If it is assumed that best practice appraisal techniques of company valuations are based on net present value of future economic cash flows, which contains both risk and uncertainty as well as value for money, but for non-financial managers, for example, ratios such as ROCE and ROE, which use accounting profit and data are more easily interpreted by the management and are preferable. The smaller company would have 
an interest in overstating its assets and understating its liabilities in order to look profitable for the interested investors. In this situation the big corporation will have interest of the financial data to be reliable and true and fair, in order appraisals to be based on this information. Here we turn our sight to the work of the auditor. In case the smaller company is audited by an assurance company, which has good reputation, that is driven by well known integrity actions of the auditor and compliance with some code of conduct, the investor would have trust in the financial statements verified with audit opinion witnessing that the information presented is correct and free of material misstatements and that the audit opinion is not biased. In such situations, many benefits could be earned by the assurance company. What if after the deal the bigger corporation, the acquirer, reaches the conclusion that as a result of the ethical work of the auditor and his fair opinion, it has made a good investment decision and is now able to see that the company acquired is even performing better and they have made a good and profitable deal. This could possibly lead to the assurance company being offered even bigger engagement in the future, the newly emerged even bigger corporation, and respectively higher fee for that. This is just an aspect of a possible positive outcome.

Strong reputations need to be actively managed and resourced long-term, reflecting the delivery of demonstrable performance criteria reinforced by effective communication with and between stakeholders. Reputation needs quality information and strong relationships. Some of the benefits of effective risk and reputation management are reduced tensions between the auditors and its stakeholders.

Costs incurred in relation to the risks of reputation must be fully acknowledged at the highest level as an integral part of the overall risk management process and an accelerator for protecting and enhancing customer, employee and shareholder value. Reputation losses can lead to a disastrous financial impact such as decrease in revenue as a result of customer losses, asset value depletion from a brand collapse, resource diversion from fixing problems increased cost of capital as a result of share premium erosion. exposure to predatory takeover, costlier compliance through regulatory interventions or even bankruptcy.
Major changes in the regulation of public accounting companies and their auditing professionals have occurred in the aftermath of, and largely due to, large corporate failures that happened in the past. Audit and other assurance independence standards and regulations are established by the profession's standard-setting bodies and the regulators of the markets in which firms operate. Disregard of the regulations, or even inadvertent failure to comply with them, exposes the companies to legal and regulatory action and loss of public trust in their work as it occurred in the previous scenario we looked at.

By complying with those regulations and creating internal risk management policies and codes of conduct, the companies are able to avoid those unfavorable situations and to avoid the costs arising from them, in the form of intangible costs such as reputation costs, and tangible such as the ones arising from litigation and loss of earnings and market shares.

The International Ethics Standards Board for Accountants, a standard-setting board of the International Federation of Accountants ("IFAC"), has established an International Code of Ethics for professional accountants (including International Independence Standards) which serves as a set of minimum standards for IFAC member bodies and firms to adopt. The Code requires from a firm or professional accountant to comply with those provisions.

The Code establishes the fundamental principles of professional ethics for professional accountants, including objectivity, and provides a conceptual framework to assist professional accountants in complying with those fundamental principles. A conceptual framework would specify an approach for a professional accountant to:

- Identify threats to compliance with the fundamental principles

- $\quad$ Evaluate the threats identified, and

- Address the threats by eliminating or reducing them to an acceptable level.

An internal policy would be based upon and would comply with the Code. As the Code is expressed in mandatory terms, policies also use mandatory language so that it conforms to the Code.

\section{Developing a policy framework}

Determining a policy approach to dealing with conflict of interest is an essential part of 
addressing the operational risks of an assurance company. A general policy and practice references are useful and relevant when a conflict of interest might arise in the conditions of the rapidly changing social context. Different key functions of such policies are to be used with the intend to reinforce each other to provide coherent and consistent approach to managing conflict of interest situations.

Proposed key functions in determining such policy are the following: (4)

- A definition of the general features of conflict-of-interest situations which have potential to put organizational and individual integrity at risk should be set

- Identification of specific occurrences of unacceptable conflict-of-interest situations

- Leadership and commitment to implementation of the conflict-ofinterest policy

- $\quad$ Awareness that assists compliance, and anticipation of at-risk areas for prevention

- Appropriate disclosure of adequate information, and effective management of conflicts

- Partnerships with other stakeholders, including contractors, clients, sponsors and the community

- Assessment and evaluation of a conflictof-interest policy in the light of experience

- Redevelopment and adjustment of policy and procedures as necessary to meet evolving situations

A policy governs relationships between firms and their assurance clients. Such a policy would address the most common relationships that firms and their personnel might have with assurance clients in order to comply with the Code.

Firms are usually responsible for implementing processes and controls to support their management and employees' compliance with independence policies and any applicable external independence requirements. This responsibility includes implementing appropriate training, confirmation, monitoring and disciplinary processes.

It is appropriate for firms to add specific provisions with a view toward making that policy more, but not less, restrictive in accordance with local independence requirements and business objectives. An assurance company might include additional processes and guidance to enhance independence compliance, as deemed appropriate.

When a breach is identified, the firm must consider whether there are any legal or regulatory requirements that apply with respect to the breach and, if so, must comply with those requirements. The firm must also consider reporting the breach to a member body, relevant regulator or oversight authority if such reporting is common practice or is expected in the particular jurisdiction.

Core principles for managing conflict of interest (4)

In the interests of maintaining public confidence in assurance companies, public certified accountants may be expected to observe in particular the following core principles in dealing with conflict-of-interest matters to promote integrity in the performance of official duties and responsibilities.

- Independent accountants should make decisions and provide advice on the basis of the relevant laws and regulations, without regard for personal gains.

- $\quad$ Public accountants should not be biased by the presence of private interests and should dispose them, or restrict the actions upon them, because those private interests could compromise the audit opinions they provide.

- Independent auditors should avoid private-capacity action which could derive an improper advantage from inside information obtained in the course of the assurance engagement, as the information is not generally available to the public. Therefore, they are required not to misuse their knowledge and resources for private gain.

- They should also not seek or accept any form of improper benefit in expectation of influencing the professional judgement and leading to biased opinions.

Transparency and scrutiny 
Certified public accountants and public organizations are expected to act in a way that will be a subject to the closest public scrutiny. Certified public accountants' private interests that could compromise the disinterested performance of their duties should be shared appropriately with the employer, in order to enable adequate control and management of a resolution.

The assurance companies should ensure consistency and an appropriate degree of openness and transparency in the process of resolving or managing a conflict-of-interest situation.

The top management of those companies should promote scrutiny of their management of conflict-of-interest situations, within the applicable internal policy and legal framework.

\section{Promoting individual responsibility}

The independent public accountants should act at all times so that their integrity serves an example to their peers and the public which is a consumer of the integrity fruits;

Independent accountants should accept responsibility for identifying and resolving conflicts in favor of the public interest when a conflict does arise.

Auditors and assurance companies are expected to demonstrate their commitment to integrity and professionalism through their application of effective conflict-of-interest policy and practice.

\section{Survey}

In February 2019, the author conducted a comprehensive survey to test the level of implementation of the proposed risk management framework and the effects on the assurance companies' operational costs of its use. The survey questioned the leadership of 20 of the auditing companies in Bulgaria. In addition, the survey questioned investors as stakeholders interested in the audit opinions to be non-biased. Their answers provide a comprehensive perspective on the level of adoption of the framework as well as the state of audit companies' reputation.

Our methodology for the survey separates the level of implementation of such framework into three categories:

1. Low level of adoption - those assurance companies are operating in accordance to the minimal requirements of the laws and regulations and more specifically to the Code of ethics.

2. Moderate level of adoption - the tone at the top is set and such risk management framework exists, but no channels for communication of conflict of interest situations and sensitive client situations are present.

3. Highly integrated - operational risk management framework has been implemented, channels for communication when such situations arise are well known by the management and employees, in case fraud or conflict of interest practices are detected. Annual independence confirmations are fulfilled by employees as they are legally obliged to comply with the codes and in order to remind them of their ethical obligations and public duties.

\section{RESULTS ON THE BEHALF OF THE LEADERSHIP OF AUDIT FIRMS}

All the respondents from the leadership of the surveyed firms represent assurance companies of different sizes. Approximately $10 \%$ of the auditing companies in Bulgaria are subsidiaries of multinational corporations. Twenty percent of the auditing companies that participated in the survey, have highly integrated mitigating operational risk management frameworks and claim that situations of conflicts of interest have been communicated through them, monitored over time and have led to a positive impact on operational, legal and personnel costs. Moreover, the risk of occurrence of litigation penalties and reputation costs is declining gradually in the long term.

For another $50 \%$, consisting of smaller international auditing firms and local auditing firms, it is claimed the level of implementation to be moderate. This is rather a result of the smaller scales of those companies and not necessary by a bad risk management function. A development of a formal framework might be costly in relation to the benefits, as the communication of the independence principals and objectivity is done directly between the tone at the top and the employees. The remaining $40 \%$ of the companies from the survey have been identified to have implemented low standard risk management framework. Taking into account the Bulgarian market and the number of employees working in such firms, it is the minimum requirements 
that are to be complied with and any other investment in such framework could result in higher costs.

\section{RESULTS ON BEHALF OF THE INVESTORS}

Thirty four investors took part in the survey. The survey methodology for them respectively divides the participants into 2 groups investors who are content with the auditors' work and who would rely upon their audit opinions; and investors who had not relied on audited opinions historically, and are skeptical to their trustworthiness and credibility. $72 \%$ of the respondents believe that the assurance companies are reliable and prompt good reputation, independence and objectivity. $28 \%$ take the opposite opinion and are skeptical to the reliability of the assurance companies.

Overall, the appearance of the assurance trustworthiness is encouraging and good auditing practices are being adopted and implemented, which might be beneficial to cost management at the audit firms.

\section{CONCLUSION}

The article looked into the challenges of management of potential operational risk costs by dealing with conflicts of interests and sensitive client situations in audit firms. Exposed were potential benefits of sticking to actions of integrity, as well as lessons learned by the common practice of the auditors. A framework addressing those risks proactively and thus minimizing the potential costs that might arise from such situations was suggested. All of the presented theories have been surveyed for effectiveness and actual application amongst the assurance companies and their leadership. The results of the survey show that all of the surveyed companies have implemented at least some of the proposed policies and procedures. The results also show that there is a general agreement among the leadership teams of the audit firms that adopting a comprehensive operational risk management framework would benefit the audit firms in the long term minimizing its costs.

\section{REFERENCES}

1. Hemrit, W. and Ben Arab, M., Journal of operational risk, Volume 7/Number 4, 71:92, Winter 2012/13

2. T. Schmit, Joan and Roth, Kendall, Cost effectiveness of risk management practices, The journal of risk and insurance, Vol. 57, No. 3, 455:470, September 1990

3. Larkin, J., Strategic reputation risk management, 2003

4. Organisation for economic co-operation and development, Managing conflict of interest in the public sector, A toolkit, 2005 